\title{
MATHEMATICAL LITERACY EXAMINATION ITEMS AND STUDENT ERRORS: AN ANALYSIS OF ENGLISH SECOND LANGUAGE STUDENTS' RESPONSES
}

\author{
Pamela Vale, Sarah Murray \& Dr Bruce Brown \\ Rhodes University
}

\begin{abstract}
Mathematical literacy is a real-world practical attribute yet students write a high-stakes examination in order to pass the subject Mathematical Literacy in the National Certificates (Vocational) $(N C(V))$. In these examinations, all sources of information are contextualised in language. It can be effortful for English second language students to decode text. The deliberate processing that is required saturates working memory and prevents these students from optimally engaging in problem solving. In this study, 15 items from an NC(V) Level 4 Mathematical Literacy examination are selected, as well as 15 student responses to each of these questions. From these responses, those which are incorrect are analysed to determine whether the error is due to insufficient mathematical literacy or a lack of English language proficiency. These results are used as an indication as to whether the examination is fair and valid for this group of students.
\end{abstract}

\section{INTRODUCTION}

In the Programme for International Student Assessment's (PISA) 2012 Mathematics Framework, mathematical literacy is defined as 'an individual's capacity to recognise, do and use mathematics, including to reason mathematically in a variety of contexts' (PISA Governing Board, 2010: 5). For the purposes of the South African National Certificates (Vocational) $(\mathrm{NC}(\mathrm{V}))$ qualification, Mathematical Literacy has been included as a subject which envisions that students will become capable of 'managing situations and solving problems in everyday life, work, societal and lifelong learning contexts' (Department of Education, 2007: 1) by making use of mathematical concepts.

According to the Department of Higher Education and Training (DHET) (2012a), the competence demonstrated by $\mathrm{NC}(\mathrm{V})$ students in Mathematical Literacy in 2011 was: NC(V) Level 2, 29\%; NC(V) Level 3, 27\%; and NC(V) Level 4, 37\%. The targets for 2012/2013 are set at $10 \%$ higher, but this still leaves every level with a pass rate below $50 \%$. Many factors will have contributed to these poor results, but if the pass rate for $\mathrm{NC}(\mathrm{V})$ Level 4 is compared to the results of the National Senior Certificate examination for which the pass rate was $85.9 \%$ in 2011 (Department of Basic Education, 2011a), it is clear that there is cause for great concern and a need for research into this subject in the $\mathrm{NC}(\mathrm{V})$ in particular.

This article will present the results of a small study conducted in an FET college. This study formed the pilot which informed the research design of a larger scale descriptive case study. Student errors in a mathematical literacy examination will be analysed according to what the most likely cause of the error is. The aim is to reveal whether these students are losing marks 
because of their lack of English language proficiency or owing to their low level of mathematical literacy. The results are not generalisable because of the small size of the sample and can only be tentatively stated, but the description of these students' errors in relation to the questions asked can reveal whether the examination questions seem fair and valid for these particular students and thereby warrant a further similar investigation on a larger scale.

\section{THE NATIONAL CERTIFICATES (VOCATIONAL)}

The National Certificates (Vocational) were introduced as a 'sister qualification' (Umalusi, 2010a: 10) to the National Senior Certificate. Technical and vocational education has a history of more than 100 years in South Africa (Wedekind, 2008), but there is no historical precedent for the newly implemented NC(V) in the South African education system (Umalusi, 2010b). The rationale for introducing this new curriculum was to provide an alternative qualification to students that will equip them with both the theoretical background and practical experience required to master a trade or technical skill (Umalusi, 2010a).

The curriculum currently offers students a selection of 18 fields of study, all of which include compulsory fundamental subjects comprising one language, Life Orientation and either Mathematics or Mathematical Literacy.

The compilers of the NC(V) course need to develop sensitivity to the ever-changing industries in which these students will be working and the course requires curricula which can rapidly be adapted in response to this. Employability in a wider sense needs to be considered for this to be achieved. A 'solid foundation of general education' (Gamble, 2003: 62) paves the way for students to become employable in a variety of settings and enables them to adapt to changing workplace demands independently. It is for this purpose that the fundamentals have been included in the curricula of all 18 fields of study.

\section{ENGLISH LANGUAGE PROFICIENCY AND MATHEMATICAL PROFICIENCY}

English second language students face an additional challenge in their NC(V) studies, namely, that of learning and being assessed in a language other than their home language. An FET college audit (Cosser, Kraak \& Winnaar, 2010: 13) revealed that the national percentage of black students in FET colleges was $96 \%$ between 2007 and 2010. While race statistics do not directly translate into language statistics, this does reveal that an overwhelming majority of students at these colleges do not have English as their home language.

The stage of English language acquisition at which students are performing, as well as their level of mathematical proficiency, will together determine how they cope with studying Mathematical Literacy in English. When evaluating the assessment of English second language students, it is essential for researchers to have an understanding both of how mathematical thinking develops from infancy as well as the process of second language acquisition.

\subsection{Second language acquisition and English as a medium of instruction}

For many students whose second language is English, part of their learning will have been in their home language. Transferring the mathematical skills they have developed in their home 
language into contexts presented in a second language therefore becomes more complicated. For these students, the movement from informal spoken to formal written mathematical language, for example, needs to occur at three levels: 'from spoken to written language, from main language to English, and from informal to formal language' (Setati, 2002: 10). This results in a complex and multi-layered challenge for vocational students.

The assessment of mathematical literacy, specifically in the final examinations, is text-based. Questions that are cognitively undemanding to a native speaker will be more demanding for a second language student (Cummins \& Swain, 1986). This is particularly true for students who are in the earlier stages of second language acquisition. The processing of speech becomes highly automatic from the earlier stages of language acquisition; however, reading requires the reshaping of these processes to 'interface with a new information source' (Crain \& Shankweiler, 1988: 167). The processing of texts requires strategies of comprehension and production that are distinct from those required for everyday oral interactions and may require specific and sustained instruction (Cummins \& Swain, 1986).

Despite the sophistication of the human brain, it is only able to process a certain limited number of pieces of information when using working memory (Tuovinen \& Sweller, 1999). Cognitive load heory (Sweller, 1988) explains the interface between mathematical literacy and English language proficiency in assessment. According to this theory, "performance on complex cognitive tasks depends on whether the amount of information presented to the [student] equals or exceeds the availability of working memory' (Barbu, 2010: 4). What this theory implies is that the devotion of cognitive resources to comprehending text would reduce the cognitive resources available for mathematical problem solving (Barbu, 2010; Lucangeli, Tressoldi \& Cendron, 1998).

While working memory has a limited capacity, long-term memory is effectively limitless (Tuovinen \& Sweller, 1999). Only two to four elements can be manipulated in working memory when the information that is presented is novel, as opposed to the seven elements possible when information is more familiar (Van Merriënboer \& Sweller, 2005). This expands, however, when long-term memory is activated during the task. Long-term memory is a store of knowledge as organised cognitive schemata. A schema 'categorises elements of information according to [the way in which] they will be used' (Sweller, Van Merriënboer \& Paas, 1998: 257). The entire schema then forms only one element to be held in working memory, allowing for more elements to be accommodated and manipulated (Van Merriënboer \& Sweller, 2005). If practiced, these schemata can become automated, thus allowing for even more efficient use of long-term memory during tasks (Van Merriënboer \& Sweller, 2005). This is not possible for working memory, where all processing is conscious (Sweller et al, 1998). Therefore the activation of schemata, particularly those that are automatised, will increase the availability of learned information during problem solving.

Sweller and colleagues (Sweller et al, 1998) used reading as an example. After sufficient practice, a reader is able to automatically process individual letters and words and, as a result, is able to attend to the meaning of a text. Less experienced readers, such as an English language learner who has not had sufficient practice, will need to devote working memory to the processing of letters and words and will then be unable to hold additional information in her or his working memory to comprehend meaning. 


\subsection{The nature of mathematical texts}

A mathematical register refers to the specialised meanings of words from a reinterpretation of vocabulary and phrases from the natural language (Cuevas, 1984). The mathematical register constitutes the 'styles of meaning and modes of argument ... rather than the words and natural language structures' (K'Odhiambo \& Gunga, 2010: 80). This mathematical speech and writing requires that students become proficient in both ordinary and mathematical English (Setati, 2002), therefore requiring a certain level of linguistic competence in the language of instruction. Patkin (2011:2) described mathematics as possessing 'unique linguistic forms' and making frequent use of key terms, such as those signifying the four operations of addition, subtraction, multiplication and division (Patkin, 2011). In fact, key terms are involved in signifying any mathematical concept, as any important concept will result in the preponderance of terms.

The language of mathematics is 'informationally dense and structurally complex' (Hammill, 2010:1). Hammill (2010) listed several characteristics of mathematical texts: complex ideas are expressed in dense noun phrases; relationships are described by verbs; special terminology often conflicts with common use of the words and logical connectives are used extensively. These complex sentences have the effect of 'obscur[ing] the presence of people, distanc[ing] the reader from the author, and portray[ing] the student as passive and mathematics as impersonal' (Hammill, 2010:1). In this mathematical discourse, rhetorical information is not explicitly stated, but is implied (Flick \& Anderson, 1980). This leads to students with English as a second language struggling to comprehend the whole meaning of a paragraph, despite comprehending each of the individual sentences (Flick \& Anderson, 1980).

It is difficult to separate the process of reading from the process of problem solving (Bergqvist $\&$ Österholm, 2010). Lewis (1989) found that the majority of errors on solving mathematical word problems occurred due to the misrepresentation of the problem structure as communicated by the text and not from errors in computation.

Mathematical texts are not only characterised by particular technical terms and grammatical structures but are frequently multimodal (Hammill, 2010). Texts almost always contain symbolic notation and graphics in addition to the text (Hammill, 2010).

Symbols serve as a type of shorthand and are a means of condensing concepts into a manageable form that can be manipulated (K'Odhiambo \& Gunga, 2010). The reading of symbols can be done as with English, from left to right. These symbols have their own syntax but share the two-dimensional characteristics of diagrams (Hammill, 2010). They act as objects and can be approached as such.

The reading of symbols requires some significant backtracking (Hammill, 2010). Hammill (2010) commented that novice readers neglect to pay attention to parentheses and select rather to focus on the individual operations. They 'respond strongly to the visual structure of symbolic mathematics, independent of the semantic content' (Hammill, 2010: 4).

In mathematics, visual images are essential as a representation of abstract phenomena (Hammill, 2010). What an image adds to the meaning of a text can frequently not be achieved by written language alone. These modes, therefore, are distinct in terms of what they are able to portray (Kress, 2000). Kress (2000:339) observed that 'Image is founded on the logic of 
display in space; writing (and speech even more so) is founded on the logic of succession in time. Image is spatial and nonsequential; writing and speech are temporal and sequential'.

It is complex and difficult to acquire meaning from visual displays, particularly when the student is offered no guidance in this regard (Hammill, 2010). The more challenging the content of the text, the more likely the student is to focus on the accompanying visual displays, and this can help to compensate for any difficulties a student may have in comprehending text (Chen, 2011). Lowrie and Diezmann (2007) explained that in order to interpret graphics successfully, students need to attend to and comprehend the mathematical content and context as well as the graphics.

\subsection{The relationship between English language proficiency and mathematical proficiency}

Barton and Neville-Barton (2003) estimated that academic performance varies according to English language ability by up to $10 \%$. Language as a 'vehicle for mathematics learning' (Barton \& Neville-Barton 2003: 4) is an important area for investigation and research as a serious and complex disadvantage is faced by students who have a poor command of the language of learning and instruction (Anthony \& Setati, 2007; Barton \& Neville-Barton, 2003).

Other than developing an understanding of the mathematical register, in order to acquire mathematical knowledge, students need to participate in the negotiation of meaning in the classroom, which also requires competent use of English (Anthony \& Setati, 2007). Cuevas (1984: 138) noted that the 'mastery of mathematical concepts presupposes some facility with the language used to express, characterise, and apply those concepts'.

In South Africa, this is particularly important as ' $[\mathrm{t}]$ he majority of [students] ... learn mathematics in a language that they are not fluent in' (Setati \& Barwell, 2008: 2). Research has revealed that the majority of students who are unsuccessful in Grade 12 are not studying in their home language (Setati \& Barwell, 2008). There are additional factors which contribute to this picture, but it is undeniable that English proficiency is related to proficiency in mathematical literacy in the South African context.

Sarah Howie's (2005) secondary analysis of the South African results of the Third International Mathematics and Science Study supports the above contention. Her key findings include that 'pupils could not communicate their answers in the language of the test' (Howie, 2005: 178) and that 'pupils who [spoke] the language of the test more frequently at home ... attain[ed] higher scores on the mathematics test' (Howie, 2005: 178). Howie's (2005) analysis indicated a variety of statistically significant factors affecting the mathematics results of the student participants: achievement on an English language proficiency test; socio-economic status; perception of mathematics; exposure to English; the teachers' view of their professional status; the mathematics teachers' beliefs about mathematics; school location; extent of English use in the classroom; teachers' time spent working and teachers' preparedness for lessons. The data, however, specifically supports her conclusion that the 'language component represented in a number of the variables' (Howie, 2005: 184) has a strong effect on achievement in mathematics. 


\section{WHAT IS MATHEMATICAL LITERACY?}

Mathematical Literacy was introduced as a subject in South Africa in the Further Education and Training (FET) phase in order to build on the mathematical content of the preceding General Education and Training Phase. The emphasis is on the use of these skills in applied contexts, which increases in difficulty and complexity as the student progresses through the FET phase, demanding higher levels of understanding and analysis (Venkatakrishnan \& Graven, 2006). Therefore, a shift is envisioned from abstract mathematics to the concrete application of mathematical skills (Venkatakrishnan \& Graven, 2006).

The Subject Guidelines: Mathematical Literacy Level 2 (DHET, 2012b: 1), defined mathematical literacy as 'an attribute of individuals ... that involves managing situations and solving problems in everyday life, work, societal and lifelong learning contexts by engaging with mathematical concepts ... presented in a wide range of different ways'. The Department of Basic Education (2011b: 10) listed the competencies that comprise mathematical literacy as 'the ability to reason, make decisions, solve problems, manage resources, interpret information, schedule events and use and apply technology'.

The range of different forms of presentation, and information to be interpreted in the NC(V) subject, are described as 'collected and organised data obtained from numbers, tables and graphs' (DHET, 2012b: 5), all of which are framed by a given context. The way in which these contexts and concepts are presented in examinations is by 'written inscription and language [which is] used to create, record and justify [mathematical] knowledge' (Anthony \& Setati, 2007: 218). Since language proficiency in English is not specified in the scope of the Mathematical Literacy curriculum, it should not interfere with students' success in the assessment of their mathematical literacy proficiency.

Polya is considered by many to be the 'father of the modern focus on problem solving in mathematics education' (Passmore, 2007: 1). In his pioneering work, How to Solve It (Polya, 1957), he outlined a process that has informed conceptions of problem solving (Organisation for Economic Co-operation and Development (OECD), 2003) and mathematical literacy (PISA Governing Board, 2010) still used today. Polya's (1957) four-stage process of problem solving consists of

1. Understanding the problem In this first step, an understanding of the unknowns, data and conditions of the problem needs to be established.

2. Devising a plan

A connection needs to be found between the unknowns and the given data to arrive at a plan for finding the solution.

3. Carrying out the plan

4. Looking back

The solution obtained by carrying out the plan must be examined for its correctness.

The authors of the framework for the PISA 2012 (PISA Problem Solving Expert Group, 2010) assessment of problem solving have derived their four problem-solving processes from Polya's (1957) work. These processes do not necessarily form a linear information 
processing system but represent parallel processes (PISA Problem Solving Expert Group, 2010). They are

1. Exploring and understanding

The problem situation is observed and interacted with in the search for information, limitations and obstacles in order to build a mental representation.

2. Representing and formulating

A coherent mental representation is formed by mentally organising information and integrating it with prior knowledge. This includes constructing tabular, graphical, symbolic or verbal representations; formulating hypotheses and critically evaluating information.

3. Planning and executing

Planning involves goal setting and devising a strategy to achieve the goal state and then carrying out this plan.

4. Monitoring and reflecting

As progress is made towards the goal state, intermediate and final results are checked with remedial action taken where necessary. On reflection, assumptions are critically evaluated and alternative solutions considered.

(PISA Problem Solving Expert Group, 2010: 20)

The PISA Governing Board (2010) described the process of solving a mathematical problem embedded in a context as mathematical literacy in practice. This is illustrated in the figure below.

\section{Figure 1: Mathematical literacy in practice}

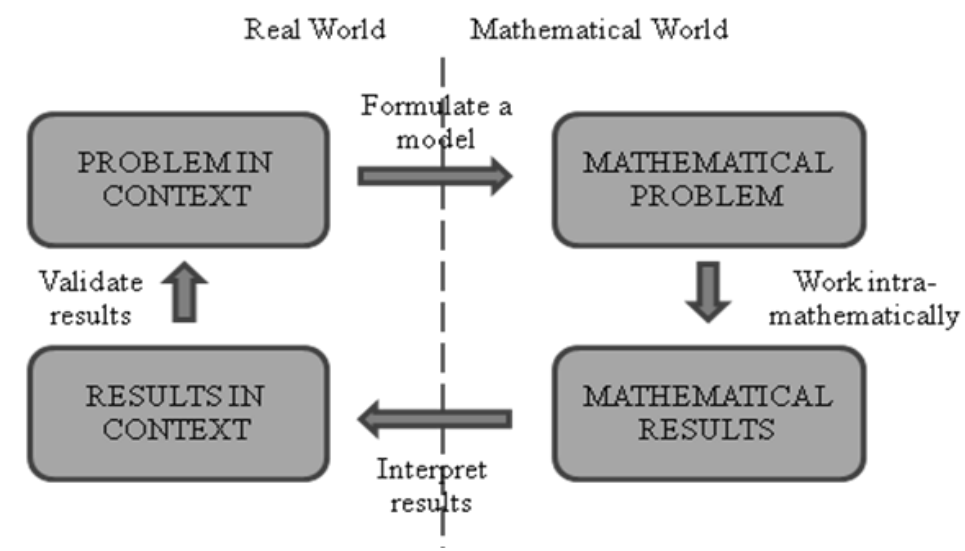

(PISA Governing Board, 2010: 6)

The process of solving such a problem begins when a problem is posed in a given real-world context, for example, the area of a floor to be tiled needs to be calculated by a contractor. The problem needs to be translated into a mathematical one by formulating a model. In this case, the model would require a procedure to calculate the area as well as knowledge of the relevant measurements. Once the model has been derived and the required information gathered, intramathematical work is done to arrive at a numerical solution. This numerical result must be interpreted in order to make the decisions for which the calculation was performed. A contractor may need the information from this example for a variety of decisions, such as to 
calculate the cost to tile this floor, in which case this information will become necessary for the next problem-solving cycle.

\section{THE ASSESSMENT OF MATHEMATICAL LITERACY}

The assessment of Mathematical Literacy in the $\mathrm{NC}(\mathrm{V})$ is divided into two components (DHET, 2012c). The Internal Continuous Assessment component is weighted as $25 \%$ of the final result, and consists of internally controlled formative tasks undertaken throughout the year. Two external examinations are written at the end of the academic year, which are together weighted as $75 \%$ of the final result.

\subsection{Fair assessment}

The latest assessment guidelines for Mathematical Literacy (DHET, 2012c) emphasise the principles of validity, as well as fairness and transparency in assessments. Methods referred to as unfair are, among others 'bias based on ethnicity, race, gender, age, disability or social class ... and comparison of students' work with other students, based on learning styles and language' (DHET, 2012c: 3).

The concept of bias and unfairness in Mathematical Literacy assessment can be extended to include instances where assessments require a high level of language proficiency in order for students to comprehend questions and formulate responses. It is possible that students whose home language is the language of learning and teaching and those who have already experienced this language as the medium of instruction may be favoured. This has an impact on the validity of assessments, as the language proficiency of the student could become what is assessed as opposed to the outcomes of the subject being examined.

Umalusi (2010c) monitors the quality of examinations and assessments for the NC(V). Their evaluation of the November $2009 \mathrm{NC}(\mathrm{V})$ examinations revealed that poor editing forced external moderators to 'grapple with poor language usage, incorrect spelling and typing errors' (Umalusi, 2010c: 17). In addition, Umalusi (2010c) found that some editors were unaware that the changes they made with regard to language and sentence structure could change the meaning of the questions. As only a sample of examination papers is externally moderated in this way, the implication is that many more poorly constructed examination papers find their way into the examination room. A student with limited language proficiency in the language of the examination will almost certainly be unable to accurately respond to such poorly constructed questions and their results, and consequently, may not accurately reflect their knowledge of that particular subject.

\subsection{Assessing English second language students}

When assessing English second language students, Cummins and Swain (1986:141) pointed out that 'educators' implicit assumptions with regard to the nature of language proficiency are by no means innocuous'. Academic difficulties can be created by educators who are ignorant of the fact that English second language students require much longer than English home language students to attain grade and/or age appropriate levels of academic language proficiency (Cummins \& Swain, 1986). Halliday (2010) emphasised that assessment is a social practice, involving power relations, and therefore the principles of justice need to be deliberately applied by considering students' language proficiency when interpreting results. 
Furthermore, mathematical literacy examinations do not merely require the processing of text, but also the interpretation of multi-modal information presented in symbolic notation, diagrams, graphs and tables (Hammill, 2010).

According to the Department of Basic Education (2011b:10), it is 'essential that the contexts students are exposed to [must be] authentic and relevant, and relate to daily life, the workplace and the wider social, political and global environments'. It is further mentioned that 'students must be able to work with actual real-life problems and resources, rather than with problems developed around constructed, semi-real and/or fictitious scenarios' (Department of Basic Education, 2011b: 10). Problem solving should not have, as a pre-requisite, an excellent command of language, but in final, high-stakes examinations, it is precisely this limited command of language in second language students that may prevent them from solving the given problems accurately.

Figure 2 gives a graphic depiction of how language proficiency can affect problem solving in an examination setting. In examinations, problems are linguistically created, and sources of information are contextualised through the use of written scenarios. The question requires decoding by reading the text as well as viewing any multimodal information. The level of students' language proficiency will either allow them to understand the context and resume the mathematical literacy problem solving process or will limit their understanding, causing them to enter the problem-solving process with inaccurate information. In the same way, once the solution has been calculated, the raw number obtained must be encoded back into the context through writing or presenting information in tables, graphs or symbolic notation.

Figure 2: Problem solving in examinations

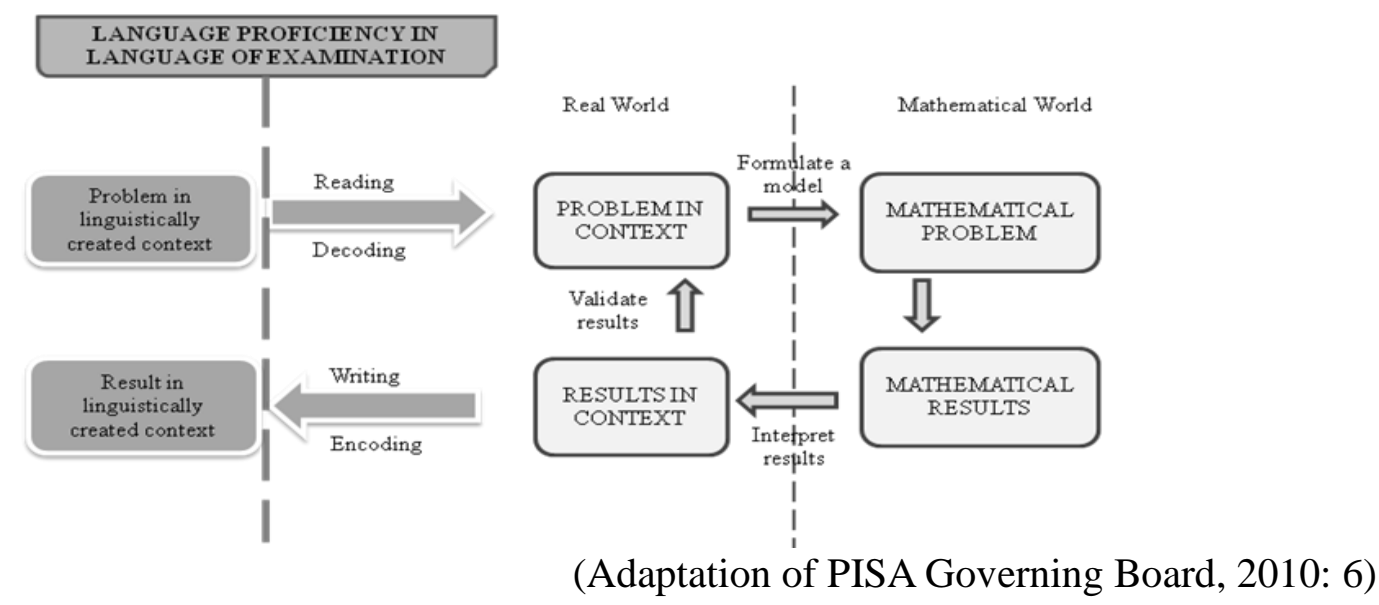

\subsection{Error analysis}

The analysis of errors has a long history in mathematics education. Students may respond incorrectly in a great variety of ways, but several models have been developed to assist in broadly identifying where the student has gone wrong. Clements (1980) pointed out that it is difficult to distinctly categorise the source of any one particular error, as they closely interact and overlap. It is, however, possible to apply a theoretical hierarchy of errors to broadly classify what might have led to the student's incorrect response. 
Data from researchers who have constructed various analysis hierarchies confirm that a frequent source of errors in written mathematical tasks is difficulty in 'reading and reading comprehension' (Clements, 1980: 13). For ESL students, the linguistic item variables, together with their own personal competence in the language, will impact on their ability to respond correctly to any item. This leads to several recognisable errors.

Newman (1977) has proposed the following error categories into which student errors on mathematical tasks can be grouped: reading; comprehension; transformation; process; encoding. Reading errors arise when a student is not able to understand the actual words or phrases used in the problem. Comprehension errors are closely related, being those that are due to the student not understanding what it is that the item required. This could be related to the language proficiency of the student, but could also be an indication that the student has not yet fully comprehended the mathematics concept involved. A transformation error occurs when a student is unable to decide what needs to be done in order to solve the problem. Processing errors involve the inability to carry out the method that has been identified as appropriate during transformation, and an encoding error results from the inability to communicate the solution, whether in written or spoken form.

Each error occurs at a specific stage in the problem-solving process. If Newman's (1977) error categories are mapped over Figure 3, the model describing problem solving in examinations, it becomes clearer where these errors can be placed in this process.

\section{Figure 3: Sources of error in mathematical literacy examinations}

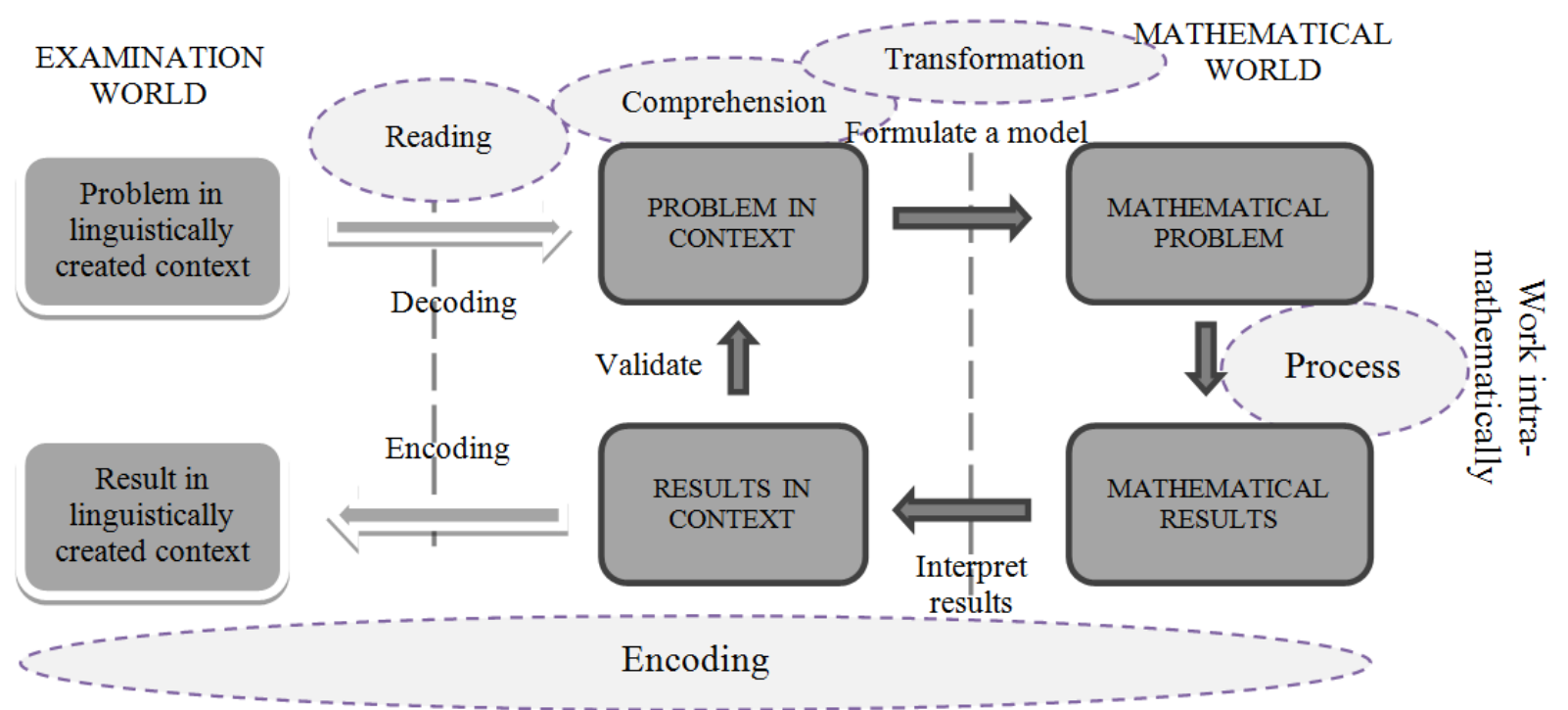

(Adaptation of PISA Governing Board, 2010: 6)

Through careful inspection of student responses to examination items, it is possible to detect which factor/s contributed to the error as well as to determine at what stage of the problemsolving process this error occurred. The particular focus of this research is to distinguish between decoding and encoding errors, as well as mathematical calculation errors, in order, to compare number of errors related to poor mathematical literacy as opposed to those related to weak English language proficiency. 


\section{RESEARCH METHODOLOGY}

\subsection{Preliminary investigation}

The stimulus for the research question was a significant drop in the class average of an $\mathrm{NC}(\mathrm{V})$ Level 3 Mathematical Literacy class when a test containing a particularly large amount of reading was administered. A focus group was held with 7 students of varying abilities from this class to investigate the possible reasons for this decrease. One question in particular had been problematic, with no student achieving more than $25 \%$ for it. When questioned, all students reported that they had struggled to understand the text. Other contributions to the discussion included the following:

- Some vocabulary was not understood (this vocabulary was not part of the mathematical terminology that students are required to know)

- A diagram would have made the text more comprehensible

- The introductory text to each question was considered confusing.

Notably, a student who had achieved above $80 \%$ for the test commented that he had struggled significantly. He mentioned that it had taken him an unusually long time and many attempts at some questions because he had not easily understood what was required of him. This was evident in his answer book, where the answer had been scratched out and attempted more than once.

If their errors were broadly grouped into those attributable to reading comprehension and limited language proficiency versus those attributable to deficient mathematical proficiency, the following results were obtained:

Figure 4: Error analysis of focus group students' test responses

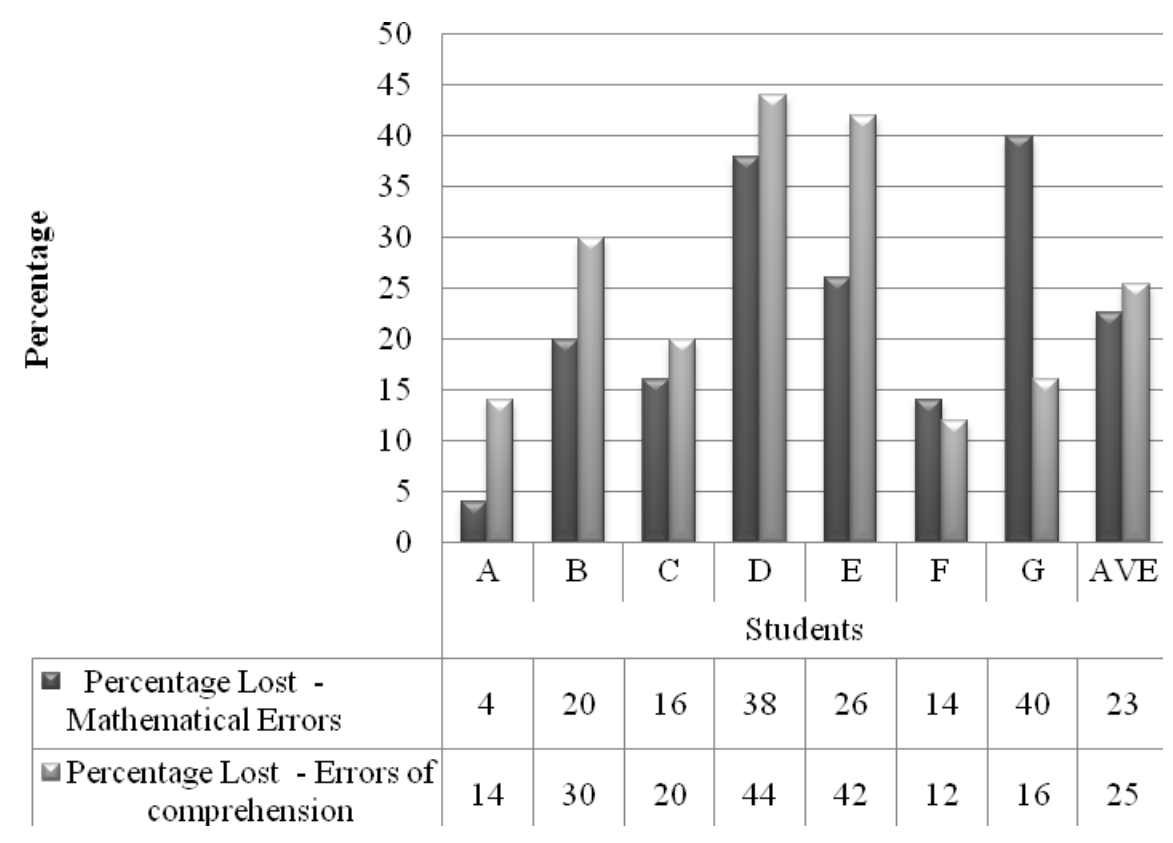

For most students, more percentage points were lost due to lack of comprehension than to mathematical errors. 


\subsection{Research design}

Following from the preliminary investigation, the aim of the research was to discover what types of errors English second language $\mathrm{NC}(\mathrm{V})$ students are making in Mathematical Literacy examinations, and at what stage in the problem-solving process these errors are occurring.

\subsubsection{Research goal and question}

The research aimed to address the following two research questions:

Question 1: What type of errors are students making?

Question 2: How do the number of mathematical literacy-related errors compare to the number of language proficiency-related errors?

\subsubsection{Participant and sample selection}

The selected examination paper had been moderated and was approved as complying with the guidelines for assessment published by the Department of Education (2007). It could therefore be assumed a suitable paper for analysis.

From this examination paper, 15 questions were selected. These questions were selected on the basis of their reading requirements, varying from a single sentence to a paragraph. They also represented a range of difficulty levels with regard to their mathematical content.

In all, 15 English second language NC(V) Level 4 students' scripts were selected for analysis. ${ }^{1}$ These students all achieved between 30 and39\% (elementary achievement) in the examination, but represented a wider range of language proficiency, with English First Additional Language results of $31 \%$ (elementary) to $51 \%$ (adequate). The scripts selected were examined to ascertain whether the student had attempted the questions or not. Those who had left out more than $30 \%$ of the examination were eliminated to allow for the largest possible number of analysable errors.

\subsubsection{Analysis of data}

After correct responses had been eliminated, 131 errors were available for analysis. Each error was attributed to one of the following categories:

- Decoding: Text (reading)

- Decoding: Graphics, tables and symbolic notation (viewing)

- Encoding: Text (writing)

- Encoding: Graphs, tables and symbolic notation (presenting)

- Mathematical proficiency

- Carelessness

Errors attributed to reading were those in which a lack of comprehension of the text contained in the problem was evident in the way in which data was interpreted and used in the calculation. Viewing errors were those in which a lack of comprehension of symbolic notation, tables or 
graphs had led to the error. It is possible to distinguish between reading and viewing errors because of the nature of mathematical texts, although both are decoding errors.

Where students struggled to translate their solutions into written form, the error was attributed to limited ability to encode information in writing. These students understood the question and were able to execute calculations correctly but failed to accurately explain the solution in writing, where this was required. Similarly, where students showed comprehension of the question and an ability to perform calculations but were unable to summarise this information accurately in symbolic form or in a table or graph, the error was attributed to a lack of ability to present data accurately, also an encoding error.

In addition to decoding and encoding errors are those in which mathematical calculation errors are made. Errors can be attributed to this category if the student demonstrates comprehension of the problem by constructing the correct mathematical model, but is unable to execute the calculation accurately. Errors may also occur due to carelessness. This was listed as the cause in cases where students demonstrated complete understanding of the problem as well as the ability to construct a mathematical model of the problem in context and calculate the result, but still made a small error due to a lack of careful calculation.

\section{RESULTS}

The number of items available for analysis was 225, of which 131 were errors analysed according to what the underlying cause was most likely to be. The results of the error analysis revealed inaccurate mathematical calculations to be the dominant source of error, accounting for $52 \%$ of the total errors. Decoding errors were also prominent: $38 \%$ of the errors were attributed to decoding, of which $26 \%$ were reading comprehension errors and $12 \%$ were viewing errors owing to a lack of comprehension of symbolic notations, tables or graphs. Encoding accounted for $7 \%$ of the errors.

The following table summarises the results of the error analysis: 
Table 1: Error attributions

\begin{tabular}{|c|c|c|c|c|c|c|c|c|c|c|}
\hline \multirow[b]{3}{*}{ NO. } & \multicolumn{9}{|c|}{ ERROR ATTRIBUTION } & \multirow[b]{3}{*}{$\underset{6}{2}$} \\
\hline & \multicolumn{2}{|c|}{ Decoding } & \multicolumn{2}{|c|}{ Encoding } & \multirow{2}{*}{ 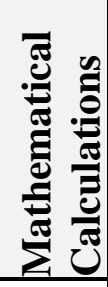 } & \multirow{2}{*}{ 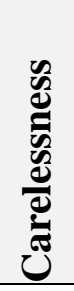 } & \multirow[b]{2}{*}{ 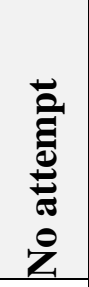 } & \multirow[b]{2}{*}{ 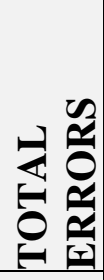 } & \multirow{2}{*}{$\begin{array}{l}0 \\
0 \\
0 \\
0 \\
0 \\
0\end{array}$} & \\
\hline & 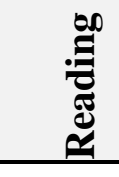 & 先 & 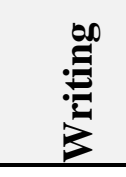 & 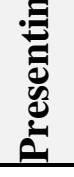 & & & & & & \\
\hline 1 & 1 & & & & 5 & & & 6 & 9 & 15 \\
\hline 2 & 2 & & & & 5 & & & 7 & 8 & 15 \\
\hline 3 & 2 & & & & 13 & & & 15 & 0 & 15 \\
\hline 4 & & & 1 & & 9 & & & 10 & 5 & 15 \\
\hline 5 & & & & & & & 1 & 1 & 14 & 15 \\
\hline 6 & & & & & & 1 & & 1 & 14 & 15 \\
\hline 7 & 1 & 10 & & & & & & 11 & 4 & 15 \\
\hline 8 & 3 & 6 & 1 & & 1 & & 1 & 12 & 3 & 15 \\
\hline 9 & 1 & & 7 & & & & & 8 & 7 & 15 \\
\hline 10 & & & & & 11 & & 1 & 12 & 3 & 15 \\
\hline 11 & 6 & & & & 2 & & & 8 & 7 & 15 \\
\hline 12 & 7 & & & & 1 & & & 8 & 7 & 15 \\
\hline 13 & 2 & & & & 11 & & & 13 & 2 & 15 \\
\hline 14 & 3 & & & & 7 & & & 10 & 5 & 15 \\
\hline 15 & 6 & & & & 3 & & & 9 & 6 & 15 \\
\hline $\begin{array}{l}\text { TOTA } \\
\mathrm{L}\end{array}$ & 34 & 16 & 9 & 0 & 68 & 1 & 3 & 131 & 94 & 225 \\
\hline$\%$ & 26 & 12 & 7 & 0 & 52 & 1 & 2 & 100 & & \\
\hline$\%$ & & & 7 & & 52 & & & & & \\
\hline$\%$ & & & & & 52 & & & & & \\
\hline
\end{tabular}


A graphic display of these results, with the categories of presenting and person variables excluded, is included below:

Figure 5: Bar graph showing percentage of errors per error attribution category

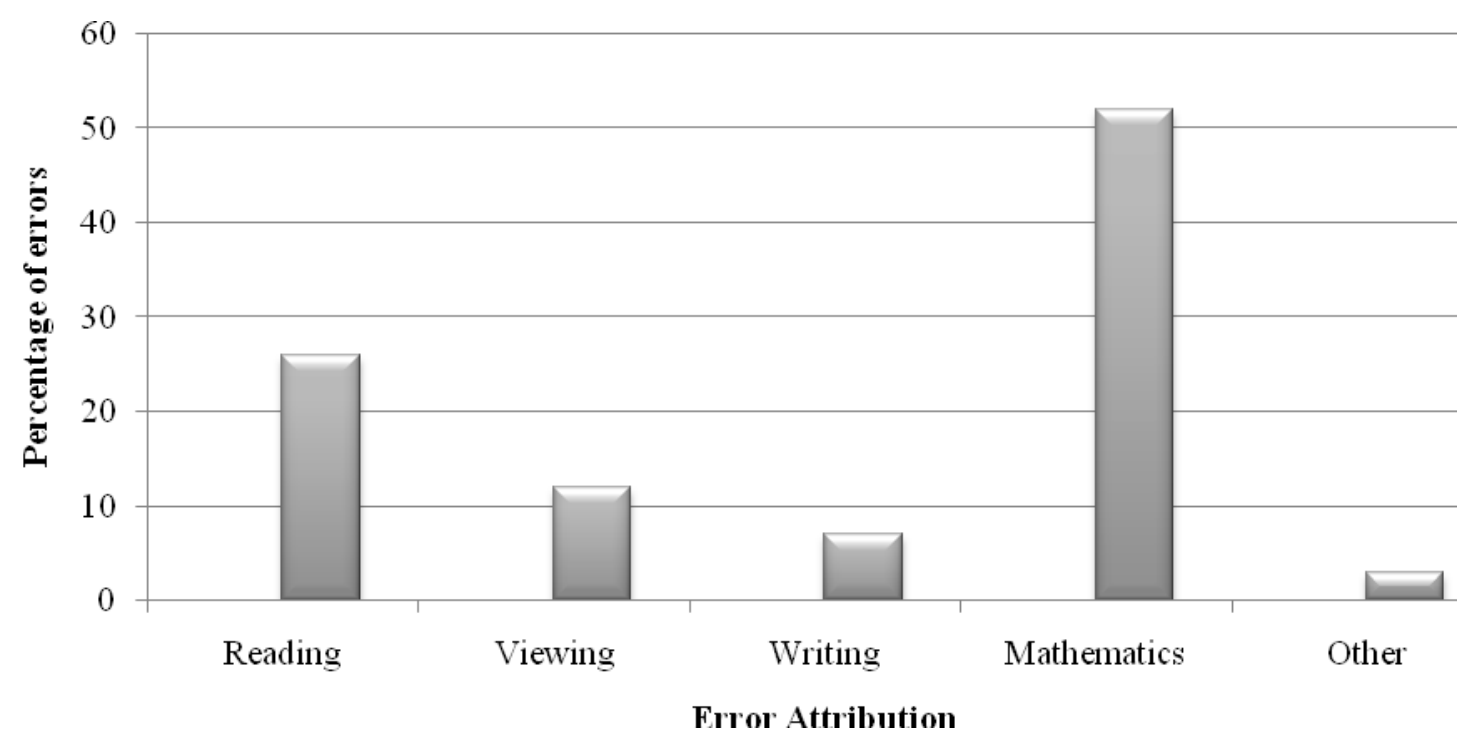

Definitions of mathematical literacy all contain an element of decoding information presented in tables, graphs, numbers and symbolic notation. According to the model used for this analysis, where mathematical literacy is lacking, the error attribution of 'viewing' is made. Therefore, if the aim of the research is to separate errors based on language proficiency versus errors made due to poor mathematical literacy, viewing needs to be incorporated into the mathematics category to create the category mathematical literacy. If this change is made, the rearranged result becomes that depicted below:

Figure 6: Percentages of mathematical literacy, reading and writing errors

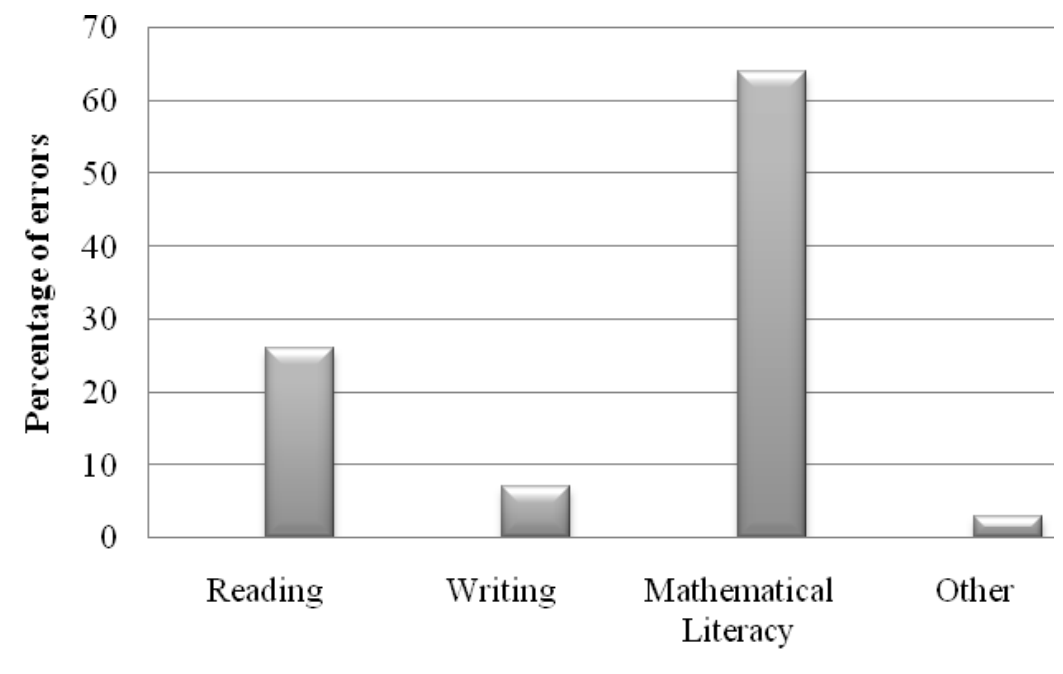

Frror Attribution

We can further simplify the picture if reading and writing is collapsed into one category: language proficiency. This allows a comparison between the percentage of the mathematical 
literacy errors made and the percentage of errors due to limited language proficiency. This is shown in the graph below.

\section{Figure 7: Mathematical literacy versus language proficiency in the attribution of errors}

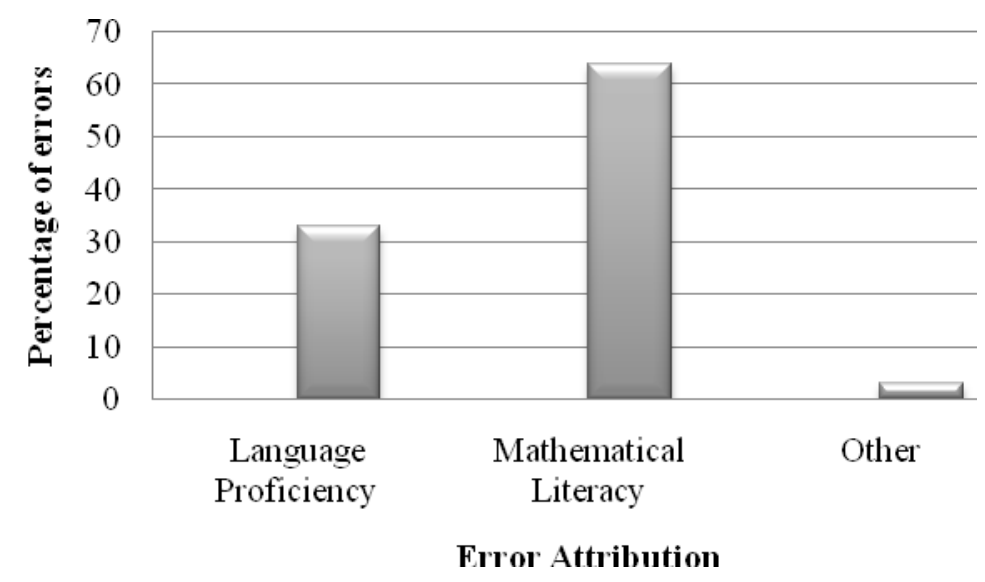

\section{DISCUSSION AND CONCLUSION}

The results of the error analysis of these students' scripts clearly reveal that a large number of errors can be attributed to lack of language proficiency. Mathematical literacy, as expected, is the largest category of error, but having $32 \%$ of the total errors due to limited language proficiency is cause for concern. This implies that the examination paper is not valid for this group of students as a measure of their mathematical literacy as a sizable part of the examination has succeeded only in revealing the students' level of English language proficiency. This calls into question the fairness of the assessment for the student population, a principle outlined in the assessment guidelines for the subject (DHET, 2012c) as being of utmost importance.

The English First Additional Language results for the students in the sample ranged from 31 to $51 \%$. A score of $51 \%$ categorises the student as achieving an' adequate result' (DHET, 2012b), but this is still low, considering the academic language demands placed on second language students by learning and being assessed in English. It is therefore not surprising that language proficiency has affected their results, but considering that all of the definitions of mathematical literacy classify it as a practical, real-world ability, the processing of English text should not determine whether a student passes or fails the subject. With the result of the final examination comprising $75 \%$ of the final mark for NC(V) Mathematical Literacy, and in light of the results of this study, it is entirely possible that this could be the case for many students.

\subsection{Concluding thoughts}

Where a lack of validity and fairness occurs in the final examinations, the consequences for students are great because of the high-stakes nature of this component. All assessment items in Mathematical Literacy, therefore, need to be carefully constructed with regard to the language demands if students' abilities and subject knowledge are to be fairly assessed. Considering the practical focus of mathematical literacy definitions, as well as the fact that the majority of the South African population are not home language English speakers, the assessment of mathematical literacy needs to be reconsidered. If written examinations are confounded by 
language problems for English second language students, either their high-stakes nature needs to be changed or a practical examination must to be introduced. Creative solutions need to be found to address this dilemma.

\section{END NOTES}

1

Permission to access the examination scripts of the 2011 Level 4 class was obtained from the Head of Department. The identity of the students whose scripts were examined was unknown to the researcher. The only stage at which the student's name was used was to eliminate those students whose mother tongue was not isiXhosa as this needed to be done according to a class list and the demographic forms completed by each student at the beginning of the year. Once this was completed, each student's script which had been selected was allocated a code for identification, and no further reference to their names was required.

\section{REFERENCES}

ANTHONY, E \& M SETATI. 2007. Exploring the English proficiency-mathematical proficiency relationship in students: An investigation using instructional English computer software. In Woo, JH, HC Lew, KS Park \& DY Seo (Eds), Proceedings of the $31^{\text {st }}$ Conference of the International Group for the Psychology of Mathematics Education in Seoul, South Korea 15 July 2007. Seoul, Korea: PME. 217-224.

BARBU, OC. 2010. Effects of linguistic complexity and math difficulty on word problem solving ability by English students. International Journal of Education,2(6):1-19.

BARTON, B \& P NEVILLE-BARTON. 2003. Investigating the relationship between English language and mathematical learning. Paper presented at the Third Conference of the European Society for Research in Mathematics Education, Bellaria, Italy 28 February- 3 March 2003.

BERGQVIST, E \& M ÖSTERHOLM. 2010. A theoretical model of the connection between the process of reading and the process of solving mathematical tasks. In Bergsten, C, E Jablonka \& T Wedege (Eds), Proceedings of MADIF-7: Mathematics and mathematics education: Cultural and social dimensions. Linköping, Sweden: SMDF. 47-57

CHEN, T. 2011. The ability of Taiwanese college freshman to read and interpret graphics in English. The Asian EFL Quarterly Journal, 13(4):300-326.

CLEMENTS, MAK. 1980. Analysing children's errors on written mathematical tasks. Educational Studies in Mathematics, 11(1):1-21.

COSSER, M, A KRAAK \& L WINNAAR. 2011. Further education and training colleges at a glance in 2010. Cape Town, RSA: Human Sciences Research Council Press.

CRAIN, S \& D SHANKWEILER. 1988. Syntactic complexity and reading comprehension. In Davison, A \& GM Green (Eds), Text comprehension: Readability issues reconsidered. London, UK: Lawrence Erlbaum. 167-192.

CUEVAS, GJ. 1984. Mathematics learning in English as a second language. Journal for Research in Mathematics Education, 15(2):134-144.

CUMMINS, J \& M SWAIN. 1986. Bilingualism in education. London, UK: Longman.

DEPARTMENT OF BASIC EDUCATION. 2011a. Report of the National Senior Certificate Examinations: National Diagnostic Report on Student Performance. Pretoria, RSA: Department of Basic Education. 
DEPARTMENT OF BASIC EDUCATION. 2011b. Curriculum and Assessment Policy Statement, Mathematical Literacy. Pretoria, RSA: Department of Basic Education.

DEPARTMENT OF EDUCATION. 2007. National Certificates (Vocational) Assessment Guidelines: Mathematical Literacy NQF Level 4. Pretoria, RSA: Department of Education.

DEPARTMENT OF HIGHER EDUCATION AND TRAINING. 2012a. Annual Performance Plan for 2012/2013. Pretoria, RSA: Department of Higher Education and Training.

DEPARTMENT OF HIGHER EDUCATION AND TRAINING. 2012b. National Certificates (Vocational) Assessment Guidelines: Mathematical Literacy NQF Level 2. Pretoria, RSA: Department of Higher Education and Training.

DEPARTMENT OF HIGHER EDUCATION AND TRAINING. 2012c. National Certificates (Vocational) Subject Guidelines: Mathematical Literacy NQF Level 2. Pretoria, RSA, Department of Higher Education and Training.

FLICK, W \& JI ANDERSON. 1980. Rhetorical difficulty in scientific English: A study in reading comprehension. TESOL Quarterly, 14(3):345-352.

GAMBLE, J. 2003. Curriculum responsiveness in FET colleges. Cape Town, RSA: Human Sciences Research Council Press.

HALLIDAY, J. 2010. Educational assessment. In Bailey, R, R Barrow, D Carr \& C McCarthy (Eds.), The SAGE handbook of philosophy of education. Thousand Oaks, CA: SAGE. 369-384.

HAMMILL, L. 2010. The interplay of text, symbols and graphics in mathematics education. Transformative Dialogues: Teaching and Learning Journal, 3(3):1-8.

HOWIE, S. 2005. Evaluating students' achievement: System-level evaluation - language and other background factors affecting mathematics achievement. Prospects, 35(2):175-186.

K'ODHIAMBO, AK \& SO GUNGA. 2010. The impact of the interaction between verbal and mathematical languages in education. Thought and Practice: A Journal of the Philosophical Association of Kenya, 2(2):79-99.

KRESS, G. 2000. Multimodality: Challenges to thinking about language. TESOL Quarterly, 34(2):337-340.

LEWIS, AB. 1989. Training students to represent arithmetic word problems. Journal of Educational Psychology, 81(4):521-531.

LOWRIE, T \& CM DIEZMANN. 2007. Middle school students' interpreting graphical tasks: Difficulties within a graphical language. In Lim, CS, S Fatimah, G Munirah, S Hajar, MY Hashimah, WL Gan \& TY Hwa (Eds), Proceedings of the 4th East Asia regional conference on mathematics education. Penang, Malaysia: Universiti Sains Malaysia. 611617.

LUCANGELI, D, PE TRESSOLDI \& M CENDRON. 1998. Cognitive and metacognitive abilities involved in the solution of mathematical word problems: Validation of a comprehensive model. Contemporary Educational Psychology, 23:257-275.

NEWMAN, MA. 1977. An analysis of sixth-grade pupils' errors on written mathematical tasks. In Clements, MA \& J Foyster (Eds), Research in mathematics education in Australia. Melbourne, Australia: Swinburne Press. 239-258. 
OECD. 2003. The PISA 2003 Assessment Framework - mathematics, reading, science and problem solving knowledge and skills. France: OECD.

PATKIN, D. 2011. The interplay of language and mathematics. Pythagoras, 32(2):1-7.

POLYA, G. 1957. How to solve it. Princeton: Princeton University Press.

PISA GOVERNING BOARD. 2010. Draft 2012 PISA Mathematics Framework. Copenhagen: Organisation for Economic Co-operation and Development.

PISA PROBLEM SOLVING EXPERT GROUP. 2010. PISA 2012 field trial Problem Solving Framework. Paris, France: OECD.

SETATI, M. 2002. Researching mathematics education and language in multilingual South Africa. The Mathematics Educator, 12(2):6-20.

SETATI, M \& R BARWELL. 2008. Making mathematics accessible for multilingual learners. Pythagoras, 67:2-4.

SWELLER, J. 1988. Cognitive load during problem solving: Effects on learning. Cognitive Science, 12:257-285.

SWELLER, J, JG VAN MERRIËNBOER \& F PAAS. 1998. Cognitive architecture and instructional design. Educational Psychology Review, 10(3):251-296.

TUOVINEN, JE \& J SWELLER. 1999. A comparison of cognitive load associated with discovery learning and worked examples. Journal of Educational Psychology, 91(2):334341 .

UMALUSI. 2010a. The ' $F$ ' in NC(V) - Benchmarking common subjects in the NSC and the $N C(V)$. Pretoria, RSA: Umalusi.

UMALUSI. 2010b. The NC(V) and the NSC: A comparative evaluation. Makoya, 8:1.

UMALUSI. 2010c. Report on the quality and assurance of the examinations and assessment for VET. Pretoria, RSA: Umalusi.

VAN MERRIËNBOER, JJG \& J SWELLER. 2005. Cognitive load theory and complex learning: Recent developments and future directions. Educational Psychology Review, 17(2):147-178.

VENKATAKRISHNAN, H \& M GRAVEN. 2006. Mathematical Literacy in South Africa and Functional Mathematics in England: A consideration of overlaps and contrasts. Pythagoras, 64:14-28.

WEDEKIND, V. 2008. Report on the research on Further Education and Training (FET) colleges in South Africa. University of Kwa-Zulu Natal, RSA: England-Africa Partnerships in Higher Education.

\section{BIOGRAPHICAL NOTE}

Pamela Vale is a PhD student of the Faculty of Education at Rhodes University. Her research interest is primarily assessment of literacy in adult education, particularly that of English second language students. She is supervised by Ms Sarah Murray and Dr Bruce Brown. Email address: pamvale83@gmail.com 